\title{
ARTESANOS HUÉRFANOS Y DESAMPARADOS: PERÚ SIGLOS XVI Y XVII
}

\author{
ORPHANS AND ABANDONED ARTISANS: PERU XVI-XVII CENTURIES
}

\author{
Marina Borges A. de Souza* y Luisa Vetter Parodi**
}

\begin{abstract}
En los últimos años, la historiografía ha venido dando mayor importancia al tema de las actividades artesanales durante el periodo virreinal en el Perú, y también ha hecho referencia al tema de los huérfanos. Sin embargo, hasta el momento no se ha dado importancia a que muchos de los artesanos y aprendices que aparecen en los documentos de los archivos eran huérfanos. La Corona española intentó ocuparse de los huérfanos europeos y también veló por aquellos que eran mestizos e indios, procurando que tuvieran un oficio para que en un futuro pudieran valerse por ellos mismos. Son diversos los tipos de documentos que nos han permitido estudiar esta situación de la orfandad y desamparo, aunque su contenido no siempre ha sido claro en cuanto a la situación real del individuo, lo que nos ha obligado a ser muy cautas con la información obtenida. Esta investigación es un primer paso en el estudio de los artesanos huérfanos y desamparados en el Perú de los siglos XVI y XVII.
\end{abstract}

Palabras clave: Artesanos, huérfanos, aprendizaje, Corona española.

Historiography is increasingly studying orphans and craft activities issues (separately though) during the colonial period in Peru, but so far it has not given importance to many of the craftsmen and apprentices appearing in documents files as orphans. The Spanish Crown tried to take care of European, mestizos and Indian orphans, making sure they had a job so in the future they could fend for themselves. Various types of documents allowed us to study the situation of orphanhood and helplessness, although its content has not always been clear about the individual's real situation, which has forced us to be very cautious about the information obtained. This research is a first step towards the study of Peru's orphan artisans at the sixteenth and seventeenth centuries.

Key words: Artisans, orphans, apprenticeship, Spanish Monarchy.

\section{Introducción}

El presente trabajo surgió de una investigación previa desarrollada por una de las autoras para su tesis doctoral titulada "El platero indio en los Andes durante los siglos XVI y XVII" (Vetter, 2013), en la que notamos el frecuente registro de aprendices de plateros que concertaban con sus maestros bajo la tutela de una autoridad local, un eclesiástico o un pariente distinto al padre. Al tratar de obtener mayor información acerca de estos aprendices huérfanos y desamparados, nos dimos cuenta que la historiografía no había tratado este tema en profundidad, por lo que nos propusimos empezar a conocer el papel que jugó la Corona española en los siglos XVI y XVII respecto del trato que se dio a los huérfanos y desamparados dentro de la sociedad virreinal, y como resultado presentamos este primer acercamiento.

\section{Los huérfanos y desamparados}

La historiografía que trata el tema del desamparo de los niños en el periodo virreinal señala que había una alta tasa de mortandad de las mujeres al momento que daban a luz. Además, las enfermedades y epidemias provocaban la muerte de miles de personas, no solamente indios sino también europeos y sus descendientes. Noble David Cook resalta que, en 1604, en la ciudad de Trujillo, costa norte del Perú, había 133 mujeres casadas, de ellas 28 tenían esposos ausentes de la ciudad en ese momento, además había 40 viudas, 45 niños huérfanos y 44 niñas huérfanas de 1.194 personas contabilizadas. Además, señala que la mitad de los niños españoles y mestizos eran huérfanos ( 89 de 171). Esta información demuestra un escenario en el que, por distintas razones, muchas mujeres y niños enfrentaron solos los sucesos de la vida cotidiana,

\footnotetext{
* Pontificia Universidad Católica del Perú, Lima, Perú. Correo electrónico: marina.souza@pucp.pe

** Pontificia Universidad Católica del Perú. Academia Nacional de Ciencias. Lima, Perú. Correo electrónico: luchivetter@hotmail.com
} 
sin el apoyo de una figura masculina o, en algunos casos, sin ningún tipo de apoyo.

La ausencia de hombres en los centros poblados durante el primer siglo de existencia del virreinato se debe a diversos factores que pasan desde su demanda para las diversas incursiones contra los muchos levantamientos que ocurrieron en el periodo, $\mathrm{y}$, por tanto, a su alta tasa de mortalidad debido a las batallas, hasta la migración forzada hacia las minas y la migración libre de los hombres a ciudades más pobladas, con un comercio más ávido y que poseían una oferta laboral más diversificada (Cook, 1989; Quiroz, 1998; Jaramillo, 1992).

\section{La Corona española y las leyes}

La situación de los niños huérfanos preocupaba a la Corona española no solamente en sus virreinatos sino también en la metrópoli, y ello se refleja en la creación de distintas leyes que buscaban regular su situación y ampararlos. De acuerdo con las Siete Partidas del rey Alfonso, cuando un niño quedaba huérfano sin que sus padres dejasen indicado en el testamento quién debería ser su curador, los parientes varones más cercanos debían hacerse cargo de su crianza. Si estos parientes no existían, un amigo cercano a la familia podía optar por ahijar/adoptar al niño, de lo contrario las autoridades locales deberían encargarse de ubicarlo en la casa de algún vecino respetable (Premo, 2005: 26). De acuerdo con dichas partidas, tan solo con la muerte del padre el niño era considerado huérfano y la madre, en una primera instancia, no podía tener la guardianía de sus hijos (Premo 2005: 25-26) ${ }^{1}$.

Las madres solamente podían ser tutoras de sus hijos si prometían en mano del rey o del juez local que mientras tuviese los niños bajo su guarda no se volvería a casar y renunciaría a la defensa que el derecho otorga a las mujeres (Las Siete Partidas, Sesta Partida, Título XVI).

\section{E la razon porque defendemos que non case} de mientra que los moçostoviere en guarda, es esta: porque podriaacaescer que por el gran amor que avria a su marido, que tomasse de nuevo, non guardariatambien las personas, ni los bienes de los moços: o faria alguna cosa, que se tornaria en gran daño dellos. (Las siete partidas, Sesta Partida, Título XVI).
En tal sentido, según las leyes de la Corona española, los responsables de los huérfanos estaban divididos en algunas categorías: los tutores, que eran quienes se encargaban de la crianza del huérfano hasta que cumpliera catorce años; los curadores, que velaban por los huérfanos de entre catorce y veinticinco años, o por aquellos huérfanos locos o desmemoriados. Además, los tutores eran los encargados de enseñarles a leer y escribir, adoctrinarlos en la religión católica, darles ropa, comida y hogar, así como garantizar que los huérfanos aprendiesen un oficio para que puedan valerse por sí mismos en el futuro ${ }^{2}$.

Otras entidades también podían encargarse de la crianza de estos niños. Era el caso de los conventos y monasterios, y en Lima, el Colegio de Niños Expósitos y el Hospital de Niños Huérfanos, el que fue fundado en 1603, siendo destinado a albergar solamente a niños blancos sin padres, sin importar el género (Las Siete Partidas; Cook, 2010; Mannarelli, 1998: 76). Casas religiosas, hospitales y colegios especiales fueron fundados y se tornaron importantes para el gobierno virreinal, pues, además, impartían la cultura europea (Burns, 2008; Mannarelli, 1998; Vergara, 2011: 101). María Emma Mannarelli rescata una interesante cita del padre Cobo sobre los niños expósitos del Hospital de los Niños Huérfanos de Lima, en la que afirma que estos niños servían en el hospital hasta alcanzar la edad de dieciocho a veinte años, y luego de esto podían ser dispuestos a vecinos de "buena fama" para que los sirviesen e instruyesen (Manarelli, 1993: 282). Si bien no queda clara la frase "sirviesen e instruyesen", pensamos que estos vecinos estaban en la posibilidad de darles instrucción en algún tipo de oficio para que pudiesen desempeñarse posteriormente como artesanos, ya sea como zapateros, plateros, sastres, entre otras múltiples posibilidades.

La ciudad de Lima ha sido el destino de muchas personas que se sentían atraídas por su dinamismo económico. De acuerdo con lo planteado por Vega (2003, 2012), durante el siglo XVI la ciudad de Lima carecía de sastres que produjesen ropa para los vecinos de la ciudad, lo que provocó que artesanos de otras regiones decidiesen migrar hacia allí y que, a la vez, empezasen a instruir a diversos aprendices que veían en este y otros oficios una oportunidad laboral ventajosa.

\section{Los huérfanos y desamparados como aprendices de oficios}

Una fuente que nos brinda información relevante acerca de los artesanos en general, y respecto de los 
artesanos huérfanos en particular, es el Padrón de Indios de Lima en 1613. Este padrón fue realizado por el virrey don Juan de Mendoza y Luna, tercer Conde de Montesclaros, con el objetivo de lograr un control más efectivo de las finanzas de la Corona en Lima. Sin embargo, este documento solo registró la información de la población indígena y mestiza de Lima, excluyendo a la población que vivía en el pueblo del Cercado (incluyendo indios portugueses, chinos y japoneses) (Cook, 1968: Introducción). Además, debido a la naturaleza administrativa del documento, la información de los huérfanos o desamparados no siempre es clara. Asimismo, ya que en la mayoría de los casos solamente se consideraba huérfano aquel que era menor de veinticinco años y soltero porque aún dependía de su curador, puede que el término no fuese utilizado cuando el artesano ya estaba casado (Premo, 2005: 40) . $^{3}$

El Padrón de Indios de Lima de 1613 también permite conocer el número de artesanos presentes en Lima durante esta época y cuántos de estos eran huérfanos. De los 642 artesanos contabilizados, sabemos que 32 eran huérfanos o desamparados (aproximadamente 4\%) ${ }^{4}$. El Padrón registra otros menores huérfanos, hombres y mujeres, aunque estos niños se encontraban bajo la tutela de una familia, en el caso que fueran muy pequeños, o estaban empleados en servicios domésticos.

Mencionamos dos ejemplos:

\section{Ej. 1. "Sedero, casado (Cochabamba).- Francisco campo oficial sedero natural de la villa de Cochabamba, no sabe quién es su encomendero ni cacique porque se ha criado con españoles. Y salió de su tierra muy pequeño, y ha nueve años que reside en esta ciudad no supo decir los que tenía pareció de treinticuatro años. Es casado con una india llamada Inés María, natural del pueblo de Acotoma, provincia de los Cheones y era su cacique [...]" (Cook, 1968: 56-57).}

Este primer caso nos deja la duda acerca de si Francisco Campo era huérfano o no, aunque hay dos situaciones posibles para entender la frase "ha sido criado con españoles": 1) que haya sido separado de sus padres a edad muy temprana por distintos motivos; 2) que haya quedado huérfano y por lo tanto se le haya asignado un vecino español como curador. Como este ejemplo tenemos muchos más en el Padrón de 1613.
El siguiente caso es más directo por cuanto menciona explícitamente que el aprendiz de sastre es huérfano.

Ej. 2. "Sastre, soltero (no sabe de donde es).- Otro indio que dijo llamarse Juan Alonso que no sabe de que pueblo es porque un clérigo llamado Diego de Cardenas que vivía en Guamanga, le crió desde pequeño y le dijo muchas veces hera huérfano y así no conoció padres encomendero ni cacique mas de el dicho padre le dijo que hera indio como lo parecía aun cortado el cabello. A cinco años que está en esta ciudad y casa donde aprende oficio de sastre no es casado y tiene dieciocho años"(Cook, 1968: 153-154).

En este pasaje podemos ver el caso de un clérigo que tuvo bajo su tutoría a un niño desamparado y, asimismo, optó por concertarle como aprendiz de un oficio siguiendo con la costumbre del período.

Otro tipo de documento que nos brinda información relevante concerniente a los artesanos huérfanos son los conciertos de aprendices. En estos ricos documentos hemos podido observar cómo los curadores legales de los huérfanos podían "traspasar" sus obligaciones a los futuros maestros artesanos. Esta afirmación se basa en diversos documentos a los que tuvimos acceso y no solamente es válida para los aprendices huérfanos, sino también para los aprendices en general. Cuando el curador legal del menor, sea este el padre, el tío, el abuelo, el hermano, o el curador asignado a los huérfanos, concertaba el asiento de aprendiz con los maestros artesanos, se acordaba que el maestro además de enseñarle el oficio, se encargaría de vestirlo (generalmente ropa de paño de Quito, calzón, camisas de Ruán, zapatos y sombrero), darle de comer, proporcionarle un lugar donde dormir, atender las enfermedades que pudiera tener hasta alcanzar quince días y, en algunos casos, se encargaría de enseñarle a leer y escribir además de las costumbres cristianas, funciones que deberían ser cumplidas por sus padres o sus curadores (ARC, PN, Escribano Meza Andueza, Prot. 196, año 1661, f. 1496 r.; AGN, PN, Escribano Alonso Hernández, Prot. 81, años 1557-1561, f. 707r.; AGN, PN, Escribano Alonso Hernández, Prot. 83, año 1563, f. 31v.-32r.). Teresa Vergara indica que los aprendices que crecían en casa de sus maestros pasaban a convertirse en miembros de 
su familia ampliada. La autoridad que el maestro ejercía le otorgaba el derecho a castigarlos y también la obligación de velar para que aprendieran un oficio que les permitiera mantenerse (Vergara, 2011: 102). Esta información es importante porque nos ofrece la oportunidad de ver con más claridad uno de los motivos por los que tantas familias con pocos ingresos optaban por hacer que sus hijos aprendiesen un oficio, porque de esta forma no tendrían que preocuparse por alimentar y vestir a una persona más ${ }^{5}$.

Pese a que la gran mayoría de los conciertos de aprendices a los que hemos tenido acceso fueron acordados entre dos personas adultas, el padre y el maestro o el curador y el maestro, debemos destacar que existen casos en que los menores se representaban a sí mismos. "García Rodríguez, español natural de la ciudad de Llerena, de trece años y huérfano de padre y madre concertó con Bartolomé Guisado, maestro platero de oro, por el tiempo de cuatro años" (AGN, Escribanía siglo XVII, Esc. Sebastián de Mendoza, Prot. 1121, años: 1652-1661, f. 1280v.). Los términos del concierto fueron similares a los ya mencionados: que el maestro le debería enseñar el oficio sin ocultarle nada, le daría de vestir, comer y donde dormir; la única particularidad es que pese a que estaba presente el alcalde ordinario de Lima al momento del acuerdo, el aprendiz huérfano menor no fue representado por él.

El hecho de que un menor se presente a sí mismo para ser aprendiz de un oficio en el periodo de estudio podía originarse solamente a partir de algunos pocos escenarios. Si el muchacho tenía menos de 14 años era sin duda huérfano; sin embargo, si el muchacho era mayor de 14 años podría ser huérfano o podía haberse trasladado solo desde un asentamiento menor a una ciudad grande buscando una mejora en sus condiciones de vida, lo que podría ser factible si ingresaba como aprendiz en el taller de algún artesano (Vergara, 2011: 101). Noble David Cook pudo observar en sus investigaciones respecto de la demografía andina del siglo XVII que gran parte de los jóvenes de sexo masculino que vivían en la ciudad de Lima habían migrado a ella, y lo más relevante es que muchos de ellos eran artesanos (Cook, 2010: 210). El oficio de artesano, incluyendo el de los maestros plateros, parecía ser una salida válida para el desempleo de aquellos que por algún motivo se vieron en una situación de desamparo en el periodo virreinal.

En el caso específico de García Rodríguez, la información es explícita acerca de su orfandad, sin embargo en otras ocasiones el hecho de que un joven mayor de 14 años se traslade solo, puede generar una mala interpretación de la información y por este motivo debemos ser muy cuidadosos al momento de analizar los conciertos de aprendices de artesanos.

De la lectura general de los documentos a los que tuvimos acceso podemos percibir que algunos de los artesanos, que en su momento ingresaron como huérfanos aprendices, llegaron a ser reconocidos en su entorno y lograron tener ingresos no solamente para mantener a su familia, sino también para tener tienda pública de su oficio y tener a su cargo otros oficiales y aprendices. Este es el caso de Pedro de Herrera, quien se vio involucrado en un pleito en la ciudad de Cusco en 1659. El pleito consistía en que Fernández Ynga, maestro ensamblador, había prestado 200 pesos a Francisco Nuflo de Romani y cuando este no pudo pagarle pidió un plazo adicional, el que le fue concedido con la condición que tuviese un fiador que en este caso fue Pedro de Herrera. Al momento de la cobranza a Pedro de Herrera, este presentó una petición de anulación de fianza en la que alegaba que era menor de 25 años y que no deberían haberle permitido firmar el compromiso. Cuando Fernández Ynga refuta la petición de Herrera afirma que este no era menor ni "hijo de familia", sino padre, maestro, dueño de tienda pública de platería y amparo de oficiales y aprendices (ARC, Cabildo del Cuzco, Causas Ordinarias, Legajo 07, cuaderno 25, años 1656-1659, f. 2v).

Con este pasaje volvemos a la problemática de las fuentes concernientes a los artesanos huérfanos que no siempre son claras y generan dudas acerca de la información. Las autoras sospechan que Pedro de Herrera era un artesano huérfano porque en el documento se utiliza la sentencia "no es hijo de familia". Si, como sospechamos, los huérfanos dejaban de denominarse como tal una vez que se casaban, esto puede significar dos cosas: 1) que Pedro de Herrera no tenía padres, o 2) que no era considerado hijo de familia ni menor justamente porque ya era padre y se sustentaba con su trabajo. Cualquiera sea el caso de este personaje, consideramos que la información presentada en el documento es relevante, debido a que un artesano pudo reunir las herramientas económicas y sociales suficientes para tener tienda pública de platería y poseer bajo su mando y amparo a otros oficiales y aprendices, posición considerada prestigiosa en el período (Vergara, 2011: 103). 


\section{Comentarios finales}

En este periodo la autoridad legal de la familia estaba concentrada en la figura paterna o en la falta de una figura masculina, que podía ser un abuelo, un hermano mayor de 25 años o una autoridad local. Sin embargo, hemos tenido acceso a algunos conciertos de aprendices en los que las propias madres e incluso una hermana presentan a los niños como aprendices. Aún no hemos podido abordar esta problemática, pero consideramos que, entre otras cosas, está relacionada a la orfandad y al hecho de que las mujeres podían obtener la guardia de menores solamente bajo autorización real y bajo la condición que mientras los niños estuviesen bajo su tutela no se podrían volver a casar.

Los conciertos de aprendices constituyeron un método utilizado por la Corona española durante el periodo virreinal para incluir y adaptar socialmente a los niños huérfanos, expósitos y desamparados, aunque la documentación existente demuestra que muchas familias pobres también optaban por incentivar a sus hijos para que se especialicen en oficios, ya que en muchos casos esto tenía un resultado positivo.

Este trabajo debe ser tomado como el punto de partida para una investigación mucho más profunda respecto de la problemática de los artesanos huérfanos y desamparados de la Colonia durante los siglos XVI y XVII, y que será desarrollada en el futuro.

\section{Agradecimientos}

Deseamos agradecer a los organizadores del Simposio "En la Memoria: Acercamiento de método. Imaginarios e Identidades actuales del pasado" del IX Congreso Internacional de Etnohistoria por la oportunidad para presentar este trabajo. Asimismo, agradecemos a la Pontificia Universidad Católica del Perú por otorgar los permisos correspondientes y por ofrecer un ambiente favorable para que se realice esta investigación.

\section{Referencias Citadas}

Burns, K.

2008 Hábitos coloniales: los conventos y la economía espiritual del Cuzco. IFEA, Lima.

Castilla

1555 [1985] Las siete partidas del sabio rey Alfonso el X, glosados por el Lic. Gregorio López. Edición facsimilar. Boletín Oficial del Estado, Madrid.

Cook, N.D

1968 Padrón de los indios de Lima en 1613. Universidad Nacional Mayor de San Marcos, Lima.

Cook, N.D.

1989 Patrones de migración indígena en el virreinato del Perú: Mitayos, mingas y forasteros. Histórica vol. XIII $\mathrm{N}^{\circ}$ 2: 125-152.

Cook, N.D.

2010 La catástrofe demográfica andina. Perú 1520-1620. Colección Estudios Andinos, Fondo Editorial PUCP, Lima. Jaramillo, M.

1992 Migraciones y formación de mercados laborales: La fuerza de trabajo indígena de Lima a comienzos del siglo XVII. Economía vol. XV No 29/30: 265-320.

Mannarelli, M.E.

1993 Pecados públicos. La ilegitimidad en Lima. Siglo XVII. Ediciones Flora Tristán, Lima.

Mannarelli, M.E.

1998 La Inquisición y el Colegio de las niñas expósitas de Santa Cruz de Atocha. Hechiceras, Beatas y Expósitas: Mujeres y poder inquisitorial en Lima, pp. 75-103. Ediciones del Congreso del Perú, Lima.

Orme, N.

2003 Medieval Children. Yale University Press, Londres.
Premo, B.

2005 Children of the Father King: Youth, Authority and Legal Minority in Colonial Lima. The University of North Carolina Press, Chapel Hill, Carolina del Norte.

Quiroz Chueca, F.

1998 El indígena urbano. Incorporación del poblador indígena a tareas económicas urbanas. Lima colonial (siglo XVI). Actas del IV Congreso Internacional de Etnohistoria Tomo I: 277-308. Fondo Editorial PUCP, Lima.

Restrepo Zea, E

2007 El concertaje laboral de los niños abandonados en Bogotá 1642-4885. Historia de la infancia en América Latina. Coordinado por Pablo Rodríguez y María Emma Mannarelli, pp. 263-279. Universidad Externado de Colombia, Bogotá.

Rosas Lauro, C.

2007 El derecho de nacer y de crecer. Los niños en la Ilustración. Perú, siglo XVIII. Historia de la infancia en América Latina. Coordinado por Pablo Rodríguez y María Emma Mannarelli, pp. 213-228. Universidad Externado de Colombia, Bogotá.

Vega Loyola, J.J.

2003 Indios inmigrantes de Trujillo en la ciudad de Lima, Siglo XVII. Tipshe año III No 3: 165-188.

Vega Loyola, J.J.

2012 De tejedores a sastres: Indígenas en Lima del siglo XVII. Tipshe año XII No 9: 195-208.

Vergara Ormeño, T.

2000 Artesanos y sirvientas: El papel de los hombres y las mujeres indígenas en la economía limeña (Siglo XVII). El hechizo de las imágenes: Estatus social, género y etnicidad en la Historia peruana. Compilado por Narda Henríquez, pp. 33-56. Fondo Editorial PUCP, Lima. 


\section{Vergara Ormeño, T.}

2011 Vivir y crecer en Lima: Niños y jóvenes indígenas en el siglo XVII. "Nosotros también somos peruanos": Lamarginación en el Perú. Siglos XVI a XXI. Editado por Claudia Rosas Lauro, pp. 94-114. Estudios Generales Letras, PUCP, Lima.
Vetter Parodi, L.M.

2013 El platero indio en los Andes: Siglos XVI y XVII. Tesis para optar al grado de Doctora en Historia con mención en Estudios Andinos, Escuela de Posgrado, Pontificia Universidad Católica del Perú, Lima.

\section{Notas}

1 Es interesante señalar el significado de la palabra huérfano registrada hasta hoy en el Diccionario de la Real Academia Española: "Dicho de una persona de menor edad: a quien se le han muerto el padre y la madre o uno de los dos, especialmente el padre". http://lema.rae.es/drae/?val=hu\%C3\%A9rfano [1 de noviembre de 2014].

2 Ejemplo representativo del concierto de huérfanos mediante la intermediación de una autoridad local son los casos de Alonso Velasco y de Hernando (mulato), cuyo curador era Antonio Sánchez, denominado como padre de huérfanos, quien asentó a ambos como aprendices de zapatero y sastre, respectivamente (AGN, Prot. Not. Siglo XVI, Escribano Alonso Hernández, Prot. 83, 1563, f. 31v-32r y 304v, 305r).

3 Salvo algunos casos particulares identificados por nosotras y por Bianca Premo en los que se utilizaba el término huérfano en beneficio propio como una estrategia legal (Premo, 2005: 40).

4 Quiroz (1998) contabiliza 780 artesanos en total, pero ha considerado pintores, pasteleros, entre otros, no considerados por nosotras.

5 Nicholas Orme (2003) ofrece información relevante acerca de este proceso en la Inglaterra del periodo medieval. 